INTERNATIONAL HIGHER EDUCATION Number 74 Winter 2014

Pages 11-12

\title{
Does a Higher Education Research Community Exist in Asia?
}

\author{
HUGO HORTA and JISUN JUNG
}

Hugo Horta is a deputy director at the Center for Innovation, Technology and Policy Research at the Technical University of Lisbon, Portugal. E-mail: hugo.horta@ist.utl.pt. Jisun Jung is a postdoctoral fellow in the Faculty of Education, University of Hong Kong, Hong Kong SAR, China. E-mail: jisun@hku.hk.

Research concerning universities and higher education has been expanding worldwide over the past few decades, but information of higher education research in Asia as a field of knowledge is scarce. While this field is small, it can illustrate key trends in Asian research development. In this context, we analyzed the higher education research community in Asia, including its evolution, poles of knowledge, and collaborations by analyzing all the articles published by Asian affiliated authors in 38 international higher education journals from 1980 to 2012 (totaling 514 articles).

According to our findings, higher education research in Asia has been growing in volume: the number of publications in higher education journals based in Asia more than tripled between the 1997-2001 and 2007-2011 periods. However, in relative terms, the research intensity of Asian-based research continues to evolve slowly and was not notably different in 2007-2011 than it was in 1997-2001 (5-7\% of the world's higher education research). This suggests that higher education research in Asia is in a relatively latent state, keeping up 
with the overall trend of growth in the world publications in higher education research.

\section{CONCENTRATED AND LIMITED}

While analyzing the field of research about higher education in Asia, several differences can be observed between countries. The 11 Asian countries, which published at least 10 publications during the period 1980-2012-Hong Kong, Japan, Malaysia, Taiwan, China, Singapore, India, South Korea, Iran, United Arab Emirates, and Saudi Arabia-account for 90 percent of all articles published in Asia in international higher education journals. Yet, substantial differences exist among these countries. Hong Kong-based higher education researchers publish almost twice as many articles than those based in Japan, which ranks second in terms of the countries with greatest production, and over five times more articles than South Korea, ranking eight. On the other hand, some countries in Asia did not account for a single publication, and these were based mostly in Central Asia. The highest concentration level of this dynamism rests in East Asia, which accounts for 50 percent of all Asian publications. This highlights significant disparities, in terms of the development of higher education in Asia, at regional and national levels.

Low levels of collaboration among Asian countries were also identified in our research, suggesting a low level of regional integration of higher education research. The internationalization of the Asian higher education scholars leans heavily toward native English-speaking countries, particularly the United States and Australia. The role that these countries have in bringing together Asian higher education researchers, to collaborate with one another, is 
disproportionately high-playing the role of research hubs for Asian higher education researchers. Asian scholars communicate more with one another through US universities than they do either through other Asian universities or directly. Collaboration with other regions of the world, such as South America or Africa is practically nonexistent. A surprising result, as it was expected that collaborations would at least be found with South American countries, that benefited from Asian Diasporas.

\section{FeW SCHOLARS FROM FeW INSTITUTIONS}

As the analysis developed, our attention was caught by the fact that a few universities in Asia had a frequent flow of publications in higher education research, while a large number of universities accounted for only one or two publications. In the last three decades, Asian universities that reported any articles only 66 percent had one article published, and 15 percent had only two articles. This unequivocally highlighted most Asian universities' infrequent participation in research about higher education. In fact, only nine (3\%) Asian universities have had at least 10 or more articles published in higher education journals, from 1980 to the present.

Even more surprising, the publication weight of some individual scholars in the overall publications of these Asian universities became apparent. In four of these nine universities, 30 percent to 60 percent of all the higher education research publications produced were due to a single academic. The importance of these individual academics was so extreme that in one case, the moving of a single academic from one university to another, led the publications in higher 
education research of the former university to wane while the latter to increase substantially.

\section{CONCLUSION}

The higher education research community in Asia is at an embryonic stage of development and mostly concentrated in East Asia. It is somewhat dispersed, unarticulated regionally, and dependent on links with outer regions of the world, particularly with English-speaking countries. The findings highlighted the still low critical mass of higher education scholars in Asia and the need for incentives to establish higher education research in universities. These incentives should not only be driven by public policies but also by Asian universities that have everything to gain by learning how to better manage themselves and contribute to the development of Asian societies.

This article is based on "Higher Education Research in Asia: A Publication and Co Publication Analysis" recently accepted in Higher Education Quarterly. See: http://onlinelibrary.wiley.com/doi/10.1111/hequ.12015/abstract. 